\title{
Upregulation of TLR4 mRNA Expression Levels in Broiler Chickens under Acute Heat Stress
}

\section{-Author(s)}

\section{Huang $S^{\prime}$}

College of Animal Science and Veterinary Medicine - Henan Agricultural University

\section{-Mail Address}

Corresponding author e-mail address Shucheng Huang

College of Animal Science and Veterinary Medicine - Henan Agricultural University, Zhengzhou, 450002, P.R. China

\section{Eeywords}

Toll-like receptors 4, liver, small intestine, acute heat stress, broiler chickens.

\section{ABSTRACT}

Toll-like receptors (TLRs) are well-characterized in mice and rats, but little is known on their role in broiler chickens during acute heat stress (AHS). The aim of the present study was to estimate the change in TLR4 mRNA expression in the liver, kidney's pleen, heart, and small intestine of broiler chickens under AHS. A total of 240 healthy Arbor Acres (AA) broiler chickens were randomly divided into four groups: control group $\left(22 \pm 1^{\circ} \mathrm{C}\right.$; Oh), HS2, HS5 and $\mathrm{HS} 10\left(38 \pm 1^{\circ} \mathrm{C} ; 2 \mathrm{~h}\right.$, 5h and $10 \mathrm{~h}$ of heat stress, respectively). As AHS duration increased, TLR4 mRNA expression slightly decreased at HS2 and HS5, but was dramatically elevated in HS10 ( $p<0.001)$ compared with the control group in the small intestine, as well as in the spleen at HS2 $(p=0.001)$ and HS10 $(p<0.001)$. The mRNA expression levels of TLR4 significantly increased in the liver, heart, and kidneys $(p<0.001)$ at HS10, and in the kidneys at HS5 $(p=0.003)$. It is found that TLR4 mRNA expression at HS10 in different organs was significantly higher $(p<0.001)$ compared with HS2 and HS5. The results of the present study suggest that AHS may modulate the functional responses of the liver, kidney, spleen, heart, and small intestine of broilers by regulating TLR4 mRNA expression.

\section{INTRODUCTION}

Heat stress (HS) may cause mortality in broilers, and it is a major economic concern as it reduces their growth performance and feed efficiency (Ryder et al., 2004). However, many animal species typically have a protective metabolism that is adapted to the optimal temperature range of the environment in which they have evolved (Zhang et al., 2014; Sun et al., 2015). It well known that poultry species, particularly broiler chickens, are more sensitive to high environmental temperatures and humidity levels than other domestic animals because of their feather cover, lack of sudoriferous glands, and fast growth rate (Piestun et al., 2013; Di et al., 2015). When the environmental temperature exceeds the optimal temperature range, broilers show signs of heat stress, including rise in body temperature, reduced feed intake, poor reproductive and growth performance, immunosuppression, and increased mortality (Kamboh et al., 2013; Zhao et al., 2013; Zhang et al., 2014; Lasagna et al., 2015; Li et al., 2015; Sun et al., 2015). Many studies have demonstrated the damage or injury of the heart, liver, and brain tissues, as well as and angiocarpy in chickens and rats under HS (Zhang et al., 2014; Quinn et al., 2015; Ito et al., 2015). Moreover, AHS triggers the expression of heat stress-related genes, such as HSP70, HSP70s, TLR2 and TLR4 (Ju et al., 2014; Zhang et al., 2014; Richter et al., 2015; Zhang et al., 2015).

Toll-like receptors (TLRs) are a family of transmembrane-spanning proteins, which recognize molecules unique to microbes, discriminate 
self from nonself antigens, trigger appropriate immune responses, act as sentinels of tissue damage, and mediate inflammatory responses to aseptic tissue injury (Takeda \& Akira, 2005; O'Neill, 2006; Marsh et al., 2009). Zhou et al. (2005) and Ju et al. (2011) have documented that the TLR4-mediated signal pathway is activated in response to stress, particularly to HS. In the present study, we hypothesized that AHS caused changes in the expression of TLR4 in different organs damaged by HS. To our knowledge, little information is available on the effect of AHS on TLR4 mRNA expression levels in various organs of broiler chickens. Thus, we investigated TLR4 gene expression in the liver, kidney, spleen, heart, and small intestine of broiler chickens subjected to AHS for different periods, providing a basis for the elucidation of the mechanism of tissue damage by AHS.

\section{MATERIALS AND METHODS}

\section{Birds}

A total of 240 one-day-old healthy Arbor Acres (AA) broiler chickens were purchased from a local commercial poultry company (Henan, China). Birds were randomly divided into four groups: control group, HS2, HS5 and HS10 (0h, 2h, 5h and 10h of HS, respectively), with six replicates of 10 broilers per cage. All broilers received a conventional commercial feed and water ad libitum until the end of the experiment.

This experiment was undertaken according to the directions of the regional Animal Ethics Committee and was approved by the Institutional Animal Care and Use Committee of Henan Agricultural University.

\section{Experimental Procedures}

On day 28, the birds of control group were observed in a separate room $\left(22 \pm 1^{\circ} \mathrm{C}\right)$, while heat-stress groups (HS2, HS5 and HS10) were allocated into another room, where the temperature was abruptly increased from $22 \pm 1^{\circ} \mathrm{C}$ to $38 \pm 1^{\circ} \mathrm{C}$ using heaters. Room relative humidity was maintained at $50 \pm 10 \%$ during the entire experiment. Six chickens were randomly selected at $0 h$, $2 \mathrm{~h}, 5 \mathrm{~h}$ and $10 \mathrm{~h}$ of the experiment from each group and killed rapidly by cervical dislocation. The liver, kidney, spleen, heart and intestinal tissues (duodenum) were dissected, placed into $2.0 \mathrm{~mL}$ cryogenic vials, frozen in liquid nitrogen, and stored at $-80^{\circ} \mathrm{C}$ until RNA isolation.

\section{RNA extraction and reverse transcription}

Total RNA was extracted from the liver, kidney, spleen, heart and small intestine collected from each group of broiler chickens. A final volume of $20 \mathrm{~mL}$ of total RNA was reversely transcribed into cDNA with a reverse transcription kit (Takara Biotechnology CO., LTD, Dalian, China), according to manufacturer's instructions at reaction temperatures of $42{ }^{\circ} \mathrm{C}$ for 40 min and $70^{\circ} \mathrm{C}$ for $15 \mathrm{~min}$. The agarose gel was run to identify the gene using the DL2000 marker.

\section{Reverse transcription-quantitative PCR (RT-PCR) for mRNA expression}

TLR4 primers were designed by the Primer Premier Software 5.0 Version (Premier Biosoft International, USA) based on known chicken sequences (Table 1). The TLR4 primers and GAPDH were synthesized from Invitrogen Biotechnology Company (China) and stored at $-80^{\circ} \mathrm{C}$ until use. The reactions were performed in a $10-\mu \mathrm{L}$ reaction mixtures containing $5 \mu \mathrm{L}$ of SYBR Greenl mix(Takara Biotechnology CO., LTD, Dalian, China), $1.25 \mu \mathrm{L}$ of diluted cDNA, $0.2 \mu \mathrm{L}$ of each primer $(10 \mu \mathrm{M})$, and $3.35 \mu \mathrm{L}$ of Rnase-free water. The PCR procedure for TLR4 with Eppendorf Real-time PCR System Mastercycler ${ }^{\circledR}$ ep realplex (Eppendorf'Germany) was performed: one cycle at $95^{\circ} \mathrm{C}$ for $2 \mathrm{~min}$, and followed by 40 cycles of $95^{\circ} \mathrm{C}$ for $20 \mathrm{~s}, 60^{\circ} \mathrm{C}$ for $20 \mathrm{~s}$, and $72^{\circ} \mathrm{C}$ for $20 \mathrm{~s}$. The relative mRNA abundance was calculated according to the method of $\Delta \Delta C t$, which accounts for gene-specific efficiencies and was normalized to the mean expressions of the above-mentioned parameters. In addition, melting curve analysis was determined to monitor PCR product purity in this experiment.

\section{Statistical Analysis}

All data were statistically analyzed using the SPSS statistical software for Windows (version 17.0; SPSS, Chicago, Illinois). The general linear model was applied for analysis of variance, and Duncan's new multiple range test was applied to compare the differences between treatments. A significance level of 0.05 was used. Data are expressed as means \pm standard error (SE).

Table 1 - Gene-specific primers used in real-time quantitative RT-PCR

\begin{tabular}{lclc}
\hline Gene & Accession number & \multicolumn{1}{c}{ Primer Sequence } & Product (bp) \\
\hline \multirow{2}{*}{ GAPDH } & \multirow{2}{*}{ K01458 } & Forward: 5'-TGAAAGTCGGAGTCAACGG -3' & 156 \\
TLR4 & AY064697 & Reverse: 5'- ACGCTCCTGGAAGATAGTGA-3' & Forward: 5'- GAGAACCTCAATGCGATGC-3' \\
& Reverse: 5'- ATAGGAACCTCTGACAACG-3' & 272 \\
\hline
\end{tabular}




\section{RESULTS}

\section{Melting curve analysis of the GAPDH and TLR4 genes}

Melting curve analyses of the GAPDH and TLR4 genes are shown in Figures $1 \mathrm{~A}$ and $1 \mathrm{~B}$. The Tm of TLR4 and GAPDH were $84.3^{\circ} \mathrm{C}$ and $86.5^{\circ} \mathrm{C}$, respectively. Moreover, PCR products produced a melting curve with a single peak at the Tm. It was indicated that RTPCR did not generate primer dimers and nonspecific amplification in the amplification process.

\section{Agarose gel analysis of the quality of the TLR4 and GAPDH genes}

Agarose gel electrophoresis for the TLR4 and GAPDH genes resulted in TLR4 and GAPDH amplicons of $272 \mathrm{bp}$ and $156 \mathrm{bp}$ in size, respectively, which are consistent with the anticipated fragment (TLR4: 200 300bp; GAPDH: 100 200bp, Figure 1C).

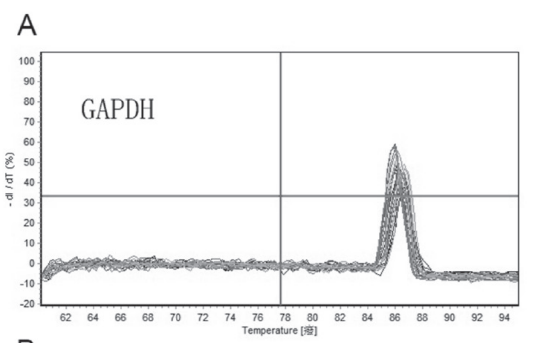

C
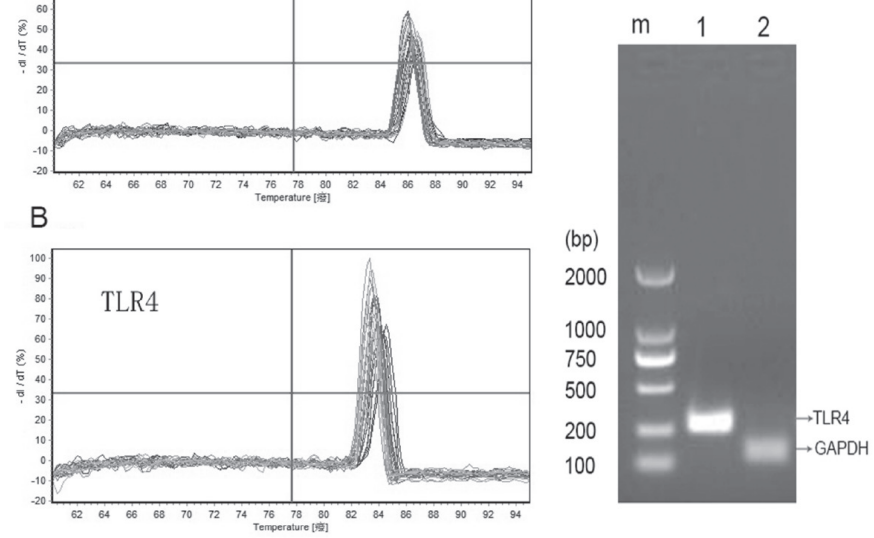

Figure 1 - Analysis of the GAPHD and TLR4 genes by melting curve $(A, B)$ and electrophoresis of agarose gel (C).

m: marker; 1: TLR4; 2: GAPDH. TLR4 and GAPDH amplicons (blue arrow) were 272bp and $156 \mathrm{bp}$ in size, respectively.

\section{Changes in TLR4 mRNA expression levels in the liver, kidney, spleen, heart and small intestine}

The TLR4 mRNA expressions levels in the liver, kidney, spleen, heart and small intestine of broiler chickens were investigated during AHS. Compared with the control group, the TLR4 mRNA expression level was slightly lower in the HS2 and HS5 groups, but dramatically elevated in the HS10 group $(p<0.001$; Figure $3 \mathrm{~A}$ ) in the small intestine, and was up to 7.139 times higher in the HS10 group than in control group. Moreover, the TLR4 mRNA expression levels in the spleen, as in the small intestine, were significantly lower $(p=0.001)$ in the HS2 group and markedly elevated in the HS10 group $(p<0.001$; Figure 3D) compared with the controls. In the liver and the heart, the TLR4 mRNA expression levels in the HS10 group were significantly higher than in the control group $(p<0.001$; Figures 3B and 3E), being 3.012 and 3.848 times higher, respectively. Additionally, the TLR4 mRNA expression levels in the kidney were markedly higher in the HS5 $(p=0.003)$ and HS10 groups $(p<0.001$; Figure 3C) than in the control group. In general, TLR4 mRNA expression levels in different organs were significantly higher $(p<0.001)$ in the HS10 group than in the HS2 and HS5 groups. These data demonstrate that AHS significantly changed the TLR4 mRNA expression levels in the liver, kidney, spleen, heart, and small intestine of broiler chickens.

\section{DISCUSSION}

Due to global warming, environmental temperatures are predicted to increase over the next decades, likely contributing to an increase in heat stress-induced organ injury and dysfunction during $\mathrm{HS}$ in animals ( $\mathrm{Yu}$ et al., 2013). This study investigated the effect of AHS on the TLR4 mRNA expression levels in the liver, kidney, spleen, heart and small intestine of broiler chickens. The results clearly show the significant effect of increasing environmental temperatures on TLR4 mRNA expression levels in different organs of broiler chickens. The TLR4 mRNA expression levels were slightly lower at HS2 and at HS5, but dramatically elevated in the small intestine at HS10 compared with the control group, not submitted to HS. Xue et al. (2011) found that the expression level of the TLR isoform TLR2 in the mucosa of the small intestine significantly increased and intestinal mucosa was damaged in rats submitted to heat stress. Fukata \& Abreu (2007) demonstrated that TLR4 induces the activation of cyclooxygenase 2 and prostaglandin E2 in vitro and in vivo, which are important for cell proliferation and apoptosis in response to intestinal mucosal injury. Gu et al. (2012) indicated that HSP7O is capable of protecting the intestinal mucosa from heat stress injury by enhancing the antioxidant capacity of broilers. Furthermore, TLR4 is involved in the recognition of endogenous or exogenous products of microbes, such as heat shock protein (HSP) and lipopolysaccharide (LPS) (Ohashi et al., 2000; Vabulas et al., 2001). Fukata et al. (2005) reported that TLR4 is important for healing the injured intestinal epithelium. Hence, the markedly increased TLR4 mRNA expression levels indicate that the 
A

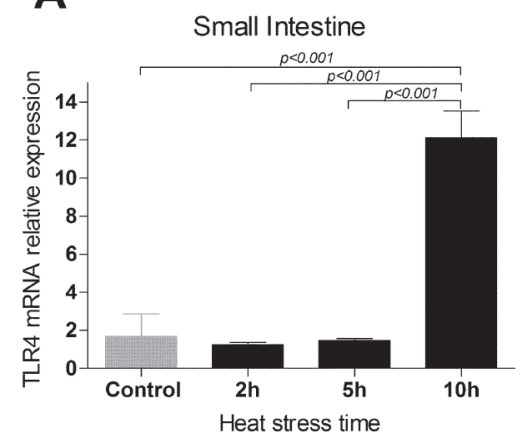

C

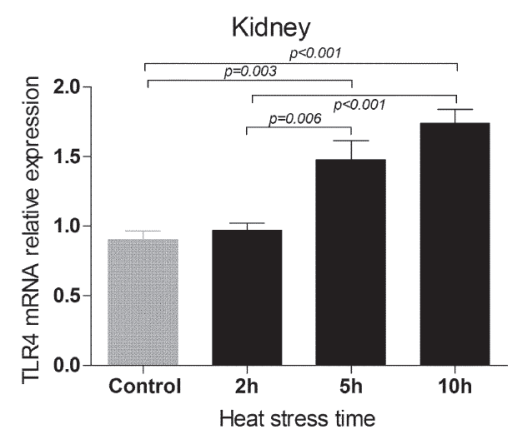

E

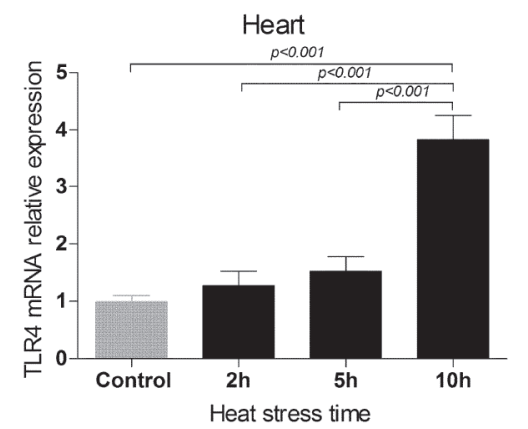

Figure 2 - TLR4 mRNA expression levels in the liver, kidney, spleen, heart and small intestine of broiler chickens under AHS.

Data are expressed as mean \pm SE $(n=6)$.

expression of HSP70 was elevated and triggered TLR4 overexpression to protect the intestine from injury by AHS.

The liver, as a major site of metabolism and detoxification, is the system of choice in studies on toxico-proteomics, metabolic disorders, and stress effects caused by various pathobiological processes. Flanagan et al. (1995) and Kregel et al. (1995) demonstrated that the liver is a sentinel organ for thermal stress. In addition, data from HS and endotoxin shock models (Ryan et al., 1994) support the critical role of the liver in the response to thermal and endotoxin challenge. During HS, a disturbance in the microecological balance of the intestinal flora may cause bacterial translocation and induce the production of intestinal endotoxins (Gu et al., 2012; Yu et al., 2013), allowing large amounts of endotoxins to reach the liver. TLR4 is stably expressed on the surface of many cells, including the Kupffer cells of the liver (Zuo et al., 2003). Zhang et al. (2009) showed that Salvia miltiorrhizae was able to significantly down regulate TLR4 expression on the surface of hepatic cells, suppress the release of the tumor necrosis factor (TNF)- $\alpha$, and mitigate the liver injury caused by excessive inflammatory reaction. In the present study, TLR4 mRNA expression level was significantly increased in the liver of HS10 broilers, indicating liver damage due to the release of TNF- $\alpha$, leading to excessive inflammatory reaction.

Altawheed et al. (2003) showed that HS can cause acute or chronic kidney failure in human patients. In animals, the kidneys play an important role in the maintenance of a stable inner environment, which can be easily disturbed by harsh environmental changes. Wolfs et al. (2002) and Anders et al. (2004) found that TLR2 and TLR4 are constitutively expressed in the epithelial cells of both proximal and distal tubules and in the mesangial cells of the kidneys in response to injury. In the present study, the TLR4 mRNA expression levels in the kidneys were markedly increased in the HS5 and HS10 groups compared with the control group, demonstrating that the kidneys were seriously impacted by AHS. In addition, previous research has shown a marked increase in TLR2 and TLR4 expression in renal tubular cells and in renal infiltrating cells caused by ischemia and reperfusion injury compared with control group (Kim et al., 2005; Pedregosa et al., 2011). Cunningham et al. (2004) reported that TLR4 expression in the kidneys was critical in mediating LPS-induced acute kidney failure via proinflammatory cytokine release and subsequent kidney damage. Those results indicate that TLR4 mRNA expression levels in the kidneys may be caused by renal tubular cells or renal infiltrating cells damage, or LPS induction under AHS. Further studies are required to elucidate the mechanism involved in the kidney injury induced by HS. 
It has been previously reported that the spleen, mainly composed by B and T lymphocytes, macrophages, and other immune cells, is a peripheral lymphoid organ that plays a critical role in innate and adaptive immune response against systemically-acquired antigens in the body (Mebius \& Kraal, 2005; Abdul-Careem et al., 2007). Ohtsu et al. (2015) showed that HS affects spleen weight and induces spleen involution in broiler chickens. Therefore, the immune function of the spleen may be affected by heat stress. Huang et al. (2014) demonstrated that nickel chloride reduced TLR4 and TLR7 mRNA expression levels in the spleen of broilers, suggesting that nickel chloride may impair innate and adaptive immune responses in the spleen. This means that down regulated TLR4 and TLR7 mRNA expression levels in the spleen are beneficial to its immune function. On the other hand, Pedregosa et al. (2011) indicated that ischemia and reperfusion injury caused a significant increase of TLR2 and TLR4 expression levels in spleen cells. In the present study, the TLR4 mRNA expression levels in the spleen were consistent with those observed in the small intestine, which were significantly reduced in the HS2 group and markedly elevated in the HS10 group. This upregulation of TLR4 mRNA expression levels in the spleen suggests that the immune function of the spleen was damaged. However, it is interesting that the down regulated TLR4 mRNA expression levels in the HS2 group indicate that the immune function was stimulated at the beginning of HS.

In the current study, the TLR4 mRNA expression levels were significantly higher in the heart of HS10 birds compared with the controls. It is well known that the activation of TLR signaling is essential for the regulation of the innate and adaptive immune systems, and results in the upregulation of inflammatory pathways and release of inflammatory cytokines, such as TNF- $\alpha$ (Konner \& Bruning, 2011). However, some non-immune cells, such as cardiac myocytes may also cause inflammation, due to their higher expression levels of TLRs, but the possible role of TLRs in this mechanism is not clear. Chao (2009) identified two TLR isoforms (TLR2 and TLR4) have on the myocyte surface, which were implicated in ischemic cardiac injury and reduced cardiac myocyte survival. In addition, the presence of significantly higher TLR4 levels in the myocardium than in the spleen and kidney of heatstressed broiler chickens in the present study suggest that TLR signaling was highly physiologically relevant to the heart. Moreover, Bopassa et al. (2008) and Deng et al. (2012) provided strong evidence that TLR4 signaling not only mediates myocardial inflammation and ischemic injury, but also contributes to cardiac dysfunction during metabolic disease. Therefore, HS lead to a marked increase of TLR4 mRNA expression levels, indicating that the cardiac function was disturbed by HS. In addition, de Laat et al. (2014) showed that the downregulation of TLR4 expression in the mammalian heart during metabolic dysfunction would facilitate improved management of cardiac sequela to metabolic syndrome and diabetes.

Overall, the results of the current study show that there is a positive regulation of TLR4 mRNA expression in the liver, kidney, spleen, heart and small intestine of broiler chickens, and that acute heat stress may cause organ injury via increased TLR4-metiated inflammation; however, this finding need to be further investigated in broiler chickens. In addition, the TLR4 mRNA expression was different among the organs of broilers submitted to 10 hours of heat stress (small intestine $>$ heart $>$ liver $>$ spleen and kidney). In those submitted to two hours of heat stress, TLR4 mRNA expression was significantly reduced in the spleen, but not in the liver, kidney, and heart, suggesting that the immune function plays a vital role at the beginning of AHS and TLR signaling is highly physiologically relevant to the organs.

\section{ACKNOWLEDGMENTS}

The authors thank the members of the Veterinary Internal Medicine Laboratory, College of Veterinary Medicine, and Huazhong Agriculture University for their help with data analysis and the Clinical Veterinary Medicine, College of Animal Science and Veterinary Medicine - Henan Agricultural University for their help with sample collection.

\section{REFERENCES}

Abdul-Careem MF, Hunter DB, Lambourne MD, Barta J Sharif S. Ontogeny of cytokine gene expression in the chicken spleen. Poultry Science 2007;86:1351-1355.

Altawheed AR, Alawadi KA, Kehinde EO, Abdulhalim H, Alhunayan A, AliY, et al. Anuria secondary to hot weather-induced hyperuricaemia:diagnosis and management. Annals of Saudi Medicine 2003;23(5):283-287.

Anders HJ, Banas B, Schlondorff D. Signaling danger:toll-like receptors and their potential rolesin kidney disease. Journal of the American Society of Nephrology 2004; 15:854-867.

Bopassa JC, Feng Y, Zou L, Chao W. Cardiac toll-like receptor 4 (TLR4) is protective against ischemia-reperfusion injury in isolated perfused hearts. Circulation 2008;118:S1473 -S1473.

Chao W. Toll-like receptor signaling:a critical modulator of cell survival and ischemic injury in the heart. American Journal of Physiology: Heart \& Circulatory Physiology 2009;296:H1-12. 
Cunningham P N, Wang Y, Guo R, He G, Quigg RJ. Role of Toll-like receptor 4 in endotoxin-induced acute renal failure. Journal of Immunology 2004;172(4):2629-2635

De Laat MA, Gruntmeir KJ, Pollitt CC, Mcgowan CM, Sillence MN, Lacombe VA. Hyperinsulinemia down-regulates tlr4 expression in the mammalian heart. Frontiers in Endocrinology 2014;5(120):120-120.

Di W, Jiao X, Song E, Shu T, Zhang X, Kemper N, et al. Acetyl salicylic acid protected against heat stress damage in chicken myocardial cells and may associate with induced hsp27 expression. Cell Stress \& Chaperones 2015;20(4):687-696

Dong B, Qi D, Yang L, Huang Y, Xiao X, Tai N, et al. TLR4 regulates cardiac lipid accumulation and diabetic heart disease in the nonobese diabetic mouse model of type 1 diabetes. Ajp Heart \& Circulatory Physiology 2012;303:H732-742

Flanagan SW, Ryan AJ, Gisolfi CV, Moseley PL. Tissue-specific hsp70 response in animals undergoing heat stress. American Journal of Physiology 1995;268:R28-R32.

Fukata M, Abreu MT. TLR4 signaling in the intestine in health and disease. Biochemical Society Transactions 2007;35(Pt 6):1473-1478.

Fukata M, Michelsen KS, Eri R, Thomas LS, Hu B, Lukasek K, et al. Tolllike receptor-4 is required for intestinal response to epithelial injury and limiting bacterial translocation in a murine model of acute colitis. American Journal of Physiology Gastrointestinal \& Liver Physiology 2005;288(5):423-429.

Gu XH, Hao Y, Wang XL. Overexpression of heat shock protein 70 and its relationship to intestine under acute heat stress in broilers: 2 . intestinal oxidative stress. Poultry Science 2012;91(4):790-799.

Huang J, Cui H, Peng X, Fang J, Zuo Z, Deng J, et al. Downregulation of tlr4 and 7 mRNA expression levels in broiler's spleen caused by diets supplemented with nickel chloride. Biological Trace Element Research 2014;158(3):353-358.

Ito K, Bahry MA, Yang H, Furuse M, Chowdhury VS. Acute heat stress upregulates neuropeptide y precursor mrna expression and alters brain and plasma concentrations of free amino acids in chicks. Comparative Biochemistry \& Physiology Part A Molecular \& Integrative Physiology 2015;187:13-19

Ju XH, Yong YH, Xu HJ, An L, Xu YM, Jiao PR, et al. Selection of reference genes for gene expression studies in PBMC from Bama miniature pig under heat stress. Veterinary Immunology and Immunopathology 2011;144:160-166

Ju XH, Xu HJ, Yong YH, An LL, Jiao PR, Liao M. Heat stress upregulation of toll-like receptors $2 / 4$ and acute inflammatory cytokines in peripheral blood mononuclear cell (PBMC) of bama miniature pigs:an in vivo and in vitro study. Animal 2014;8(9):1462-1468.

Kamboh AA, Hang SQ, Bakhetgul M, Zhu WY. Effects of genistein and hesperidin on biomarkers of heat stress in broilers under persistent summer stress. Poultry Science 2013;92:2411-2418.

Kim BS, Lim SW, Li C, Lim JS, Sun BK, Ahn KO, et al. Ischemia-reperfusion injury activates innate immunity in rat kidneys. Transplantation 2005; 79:1370-1377.

Könner AC, Brüning JC. Toll-like receptors: linking inflammation to metabolism. Trends in Endocrinology \& Metabolism: Tem 2011;22(1):16-23.

Kregel KC, Moseley PL, Skidmore R, Gutierrez JA, Guerriero V. Hsp70 accumulation in tissues of heat-stressed rats is blunted with advancing age. Journal of Applied Physiology 1995;79(5):1673-8.
Lasagna E, Rimoldi S, Ceccobelli S, Marelli SP, Cozzi MC, Sarti FM, et al. The genetic of welfare:gene expression and heat stress in chicken. Italian Journal of Animal Science 2015;14(1):7.

Li M, Wu J, Chen Z, Li M, Wu J, Chen Z. Effects of heat stress on the daily behavior of wenchang chickens. Revista Brasileira de Ciência Avícola 2015;22(1):11-19

Marsh BJ, Williams-Karnesky RL, Stenzel-Poore MP. Toll-like receptor signaling in endogenous neuroprotection and stroke. Neuroscience 2009;158:1007-1020

Mebius RE, Kraal G. Structure and function of the spleen. Nature Reviews Immunology 2005;5(8):606-616.

O'Neill LAJ. How Toll-like receptors signal:what we know and what we don't know. Current Opinion in Immunology 2006;18:3-9.

Ohashi K, Burkart V, Flohé S, Kolb H. Cutting edge: heat shock protein 60 is a putative endogenous ligand of the toll-like receptor-4 complex. Journal of Immunology 2000;164(2):558-561.

Ohtsu H, Yamazaki M, Abe H, Murakami H, Toyomizu M. Heat stress modulates cytokine gene expression in the spleen of broiler chickens. Journal of Poultry Science 2015;52(4):282-287.

Pedregosa JF, Haidar AA, Hirata AE, Franco M, Gomes GN, Bueno, V. TLR2 and TLR4 expression after kidney ischemia and reperfusion injury in mice treated with fty720. International Immunopharmacology 2011;11(9):1311-1318

Piestun Y, Druyan S, Brake J, Yahav S. Thermal manipulations during broiler incubation alter performance of broilers to 70 days of age. Poultry Science 2013;92(5):1155-63

Quinn CM, Audet GN, Charkoudian N, Leon LR. Cardiovascular and thermoregulatory dysregulation over $24 \mathrm{~h}$ following acute heat stress in rats. American Journal of Physiology Heart \& Circulatory Physiology 2015;309(4):91-95

Richter C, Viergutz T, Schwerin M, Weitzel JM. Prostaglandin e synthase interacts with inducible heat shock protein 70 after heat stress in bovine primary dermal fibroblast cells. Cytometry Part A 2015;87(1):61-67.

Ryan AJ, Matthes RD, Mitros FA, Gisolfi CV. Heat stress does not sensitize rats to the toxic effects of bacterial lipopolysaccharide. Medicine \& Science in Sports \& Exercise 1994;26:687-694.

Ryder AA, Feddes JJR, Zuidhof MJ. Field study to relate heat stress index to broiler performance. Journal of Applied Poultry Research 2004;13(3):493-499.

Sun L, Lamont SJ, Cooksey AM, Mccarthy F, Tudor CO, Vijay-Shanker K, et al. Transcriptome response to heat stress in a chicken hepatocellular carcinoma cell line. Cell Stress \& Chaperones 2015;20(6):1-12.

Takeda K, Akira S. Toll-like receptors in innate immunity. International Immunology 2005;17(1):1-14.

Vabulas RM, Ahmad-Nejad P, Costa C, Miethke T, Kirschning CJ, Häcker $\mathrm{H}$, et al. Endocytosed HSP60s use toll-like receptor 2 (TLR2) and TLR4 to activate the toll/interleukin-1 receptor signaling pathway in innate immune cells. Journal of Biological Chemistry 2001;276(33):3133231339

Wolfs TGAM, Buurman WA, Van Schadewijk A, Vries BD, Daemen MARC, Hiemstra PS, et al. In vivo expression of toll-like receptor 2 and 4 by renal epithelial cells:IFN- $\gamma$ and TNF- $\alpha$ mediated up-regulation during inflammation. Journal of Immunology 2002;168:1286-1293.

Xue S, Mu D, Dai J, Wang Z, Zhao H, Yuan Y, et al. Preventive effect of glutamine combined with vitamin c on intestinal endotoxemia induced 
by heat stress in rats. Journal of Third Military Medical University 2011;33(17):1779-1782.

Yu J, Liu F, Yin P, Zhao H, Luan W, Hou X, et al. Involvement of oxidative stress and mitogen-activated protein kinase signaling pathways in heat stress-induced injury in the rat small intestine. Stress: The International Journal on the Biology of Stress 2013;16(1):99-113.

Zhang WW, Kong LN, Zhang XQ, Luo QB. Alteration of HSF3 and HSP70 mRNA expression in the tissues of two chicken breeds during acute heat stress. Genetics \& Molecular Research 2014;13(4):9787-9794.

Zhang LJ, Wang KF, Jing YP, Zhuang HM, Wu G. Identification of heat shock protein genes HSP70s and HSP70 and their associated mRNA expression under heat stress in insecticide-resistant and susceptible diamondback moth, plutella xylostella (lepidoptera:plutellidae). European Journal of Entomology 2015;112(2):215-226
Zhang X, Liu D, Wu D, Zhu C, Ye J, Wang K, et al. Effect of salvia miltiorrhizae on the expressions of tir4 protein in the liver of rats with SAP or OJ. Inflammation 2009;32(3):151-162.

Zhao W, Wisniewski M, Wang W, Liu J, Liu Y. Heat-induced oxidative injury contributes to inhibition of Botrytis cinerea spore germination and growth. World Journal of Microbiology \& Biotechnology 2013;30(3):951-957

Zhou J, An H, Xu H, Liu S, Cao X. Heat shock up-regulates expression of Toll-like receptor- 2 and Toll-like receptor- 4 in human monocytes via p38 kinase signal pathway. Immunology 2005;114:522-530.

Zuo GQ, Xi JP, Liu CA. Wu CX, Li SW, Dai L. Synthesis of Toll-like receptor 4 in Kupffer cells and its role in alcohol-induced liver disease. Chinese Medical Journal 2003;116(2):297-300. 
